Unfortunately, no heights are given, and there are many errors in the geographical co-ordinates of the stations, some of considerable magnitude. The remainder of the meteorological section of the volume is devoted to an important paper by $\mathrm{H}$. Helm Clayton on "Atmospheric Circulation and the Weather in Argentina.'

The hydrometric section was founded in July, I902, and there are now rog gauges at work on the principal rivers and lakes, daily forecasts being made of the probable height at important points. The elevation of the underground water is also gauged at twenty-two stations. The magnetic branch of the service was established in I904, with a central station at Pilar, near Cordoba, in charge of Mr. L. G. Schultz, who, with assistants, prosecuted field-work at regular intervals, notably in 1908 and during 1912-I3. This work is "sufficient to give a very fair knowledge of the values of the magnetic elements in all parts of the country, as well as their respective secular variations." Lines of equal declination, inclination, horizontal intensity, and vertical intensity for the epoch January, I9I4, are given in graphic form, while mean hourly values of the principal magnetic elements registered at Pilar from 1905 to $19 r_{4}$ are shown for the months, seasons, and the year (pp. 56-145). Bulletin No. 5 contains a condensed summary of the magnetic results with special reference to the field-work accomplished. Vol. xv. of the Anales contains the hourly and other meteorological observations made in Buenos Aires from 1877 to 1910 , in continuation of the series published in vol. i. of the Anales. The printing of the discussion, which is ready, has been meanwhile postponed owing to the reduction of appropriations.

The hourly meteorological and magnetic observations made at Laurie Island, South Orkneys (lat. 6 $\mathrm{I}^{\circ} \mathrm{S}$.), from 1905 to 1910 , with a discussion of all the available material since 1903 , appears in vol. xvii. of the Anales. This station was taken over in February, 1904, from the Scottish National Antarctic Expedition, and is now completing. its thirteenth year under Argentine auspices. The maintenance of this observatory involves the dispatch every summer of a relief expedition from Buenos Aires. The climate of the South Orkneys is in general insular from October to March, and continental during the rest of the year, when the surrounding seas are frozen. At all seasons the island is enveloped in a current of Antarctic origin, so that the mean temperature of the warmest month (February) does not exceed $0 \cdot 6^{\circ} \mathrm{C}$. The coldest month is July, with a mean of $-I I .9^{\circ} \mathrm{C}$., and the mean annual temperature is $-4.4^{\circ} \mathrm{C}$. The extremes noted have been $8.8^{\circ}$ and $-40^{\circ}$. Föhn is not uncommon, and during its occurrence the temperature, even in midwinter, rises considerably. The mean annual pressure is $744 \mathrm{~mm}$., with extreme readings of 774.7 and 709. $\mathrm{Imm}$. Pressure is low from January to May, and again in November, and relatively high from June to October, and also in December there is much cloud and the air is very humid. Storms are comparatively rare, and are most common at the equinoxes, and least frequent at the solstices. The station lies in the westwind system, and winds from the east are seldom observed. The upper currents are also from the west, and the cloud drift becomes more and more towards the east as the height increases. The lower clouds are at a greater height in summer than in winter. The precipitation, mostly in the form of snow, and difficult to measure owing to drift, amounts to $447 \mathrm{~mm}$. ( 17.60 in.) annually. The snow is deepest a month before the winter solstice, and in some summers does not disappear at sea-level. The diurnal range of all the elements, although distinct, is very small. An interesting chapter on the frequency and distribution of the ice in the seas surrounding the South Orkneys, showing the very variable conditions experienced from year to year, concludes the meteorological summary of the results. The rest of the volume is taken up with a discussion of the magnetic data to IgI2. The analysis of the whole material is very complete, and there are twenty-two plates, some of which possess new features.

Bulletin No. 4, by Prof. Bigelow, as the title suggests, is highly mathematical, and does not lend itself to condensation.

R. C. M.

\section{A PLAGUE OF VOLES IN ITALY, AND ITS CONTROL.}

DURING the past summer the province of Foggia in Apulia has suffered great depredations by field-voles (Pytymys savii), the grain crop having been almost entirely destroyed. Prof. Splendore has given an account (in two papers in Rendiconti $R$. Accad. Lincei, Classe fis. mat. nat., vol. xxv., July and August, 1916) of his investigations, carried out in Prof. Grassi's laboratory in Rome, with the view of finding some method of destroying the voles. Of about forty voles sent to him from Cerignola (province Foggia), some died en route, and had been partially eaten by the survivors; the others died a few davs after arrival in Rome. In all these a coccobacillus was present in the blood, in the internal organs, and in the lymphatic glands. Around Cerignola there was a remarkably high mortality among the voles, attributed by Prof. Splendore to the coccobacillus which was found in all the voles examined. This spontaneous epizootic, which spread extensively, presents the features of a septicæmia, the internal organs being congested, especially the spleen and liver, which are always enlarged. Prof. Splendore has compared the coccobacillus with Bacillus typhi murium and the typhi-coli group, and considers that it presents such clear differences as to justify him in placing it, provisionally at least, in a new species-Bacterium pytymysi.

Healthy, well-nourished voles from a locality where the epizootic was not known to occur died in less than twenty-four hours after subcutaneous inoculation with an emulsion of the spleen or liver of an infected vole; others fed with infected material died in three or four days. When dead or infected voles were placed among healthy ones, the latter developed the disease in a few days. The organism was found to be pathogenic also to mice, rats, and rabbits.

Prof. Splendore isolated the organism from the in testine of fleas found on an infected vole. The intestinal contents of three similar fleas were inoculated subcutaneously into a healthy vole, which died in less than twenty-four hours. Another healthy vole, placed in a vessel with three vole-fleas, died three days later. Both voles were found to exhibit the usual congestion of the internal organs and to contain the coccobacillus. Prof. Splendore considered that these experiments confirmed his previous suspicion that the natural method of propagation of the infection is by means of fleas. He recommended that voles infected by inoculation should be distributed in the areas in. vaded by voles, where the epizootic has not yet appeared, so that the disease would be propagated by fleas and would continually extend until the areas were freed from the rodents. It will be interesting to see how far this method has been successful in ridding the country of a destructive pest. Possibly the new organism may be found useful in attacking other species of destructive rodents, e.g. rats, but investigations will no doubt first be made as to its pathogenic relations to domestic animals and man.

No. $246 \mathrm{I}$, VOL. 98$]$ 